\title{
Tapia Syndrome after Cervical Laminoplasty: A Case Report and Literature Review
}

\author{
Seungwoo Hong ${ }^{1}$, Keung Nyun $\mathrm{Kim}^{2}$, Seong $\mathrm{Yi}^{2}$ \\ ${ }^{1}$ Department of Neurosurgery, National Health Insurance Corporation Ilsan Hospital, Yonsei University College of Medicine, \\ Goyang, Republic of Korea \\ ${ }^{2}$ Department of Neurosurgery, Spine and Spinal Cord Institute, Severance Hospital, Yonsei University College of Medicine, \\ Seoul, Republic of Korea
}

Corresponding author: Seong $\mathbf{Y i}$

Department of Neurosurgery, Spine and Spinal Cord Institute, Severance Hospital, Yonsei University College of Medicine, 50-1,

Yonsei-ro, Seodaemun-gu, Seoul 03722,

Republic of Korea

Tel: $+82-2-2228-2155$

Fax: +82-2-393-9979

E-mail: YISEONG@yuhs.ac

Received: July 8, 2021

Revised: August 10, 2021

Accepted: August 11, 2021

\begin{abstract}
We present a case report of very rare and unfamiliar disease named Tapia syndrome characterized by concomitant unilateral paralysis of the $10^{\text {th }}$ and $12^{\text {th }}$ cranial nerves. Symptoms include dysphonia, dysphagia, tongue deviation toward affected side. The syndrome occurs after orotracheal intubation. A case report of the patient; A 48-year-old Asian man, presented with both arm numbness and gait disturbance for 1 year. We planned laminoplasty of cervical 4, 5, 6, and 7. After the operation, he complained of hoarseness and difficulty in swelling. On his physical examinations, uvula and tongue deviation to right is detected. At 8 months after the surgery, his clinical symptoms and chief compliant about surgery had disappeared. The mechanism of the disease is unclear. Though the progress of the disease is benign, further evaluation to rule out other desperate disease like cerebral infarction is evitable.
\end{abstract}

Key Words: Hypoglossal nerve diseases; Intubation; Laminoplasty

\section{INTRODUCTION}

Tapia syndrome is characterized by the concomitant unilateral paralysis of the tongue and the vocal cord after orotracheal intubation. After Antonio Garcia Tapia first named this syndrome in 1904, less than a hundred cases were reported. The cause of this disorder is suggested to be compression injury of the $10^{\text {th }}$ and $12^{\text {th }}$ cranial nerves in extracranial portion. Therefore, we can say that this syndrome belongs to peripheral postoperative neuropraxia of the lower cranial nerves. Symptoms include dysphonia, dysphagia, tongue deviation toward affected side.

We present a patient who suffered from this syndrome after posterior approached cervical spine surgery. Thanks to previous reports, we can early figure out what happened to our patients and report the progress of the disease more precisely as visualized data. In this article we are going to show our case focusing on these objective materials.

Although the rarity of the disease, there is still controversy over the clear cause and treatment of the disease. We'd like to present the first comprehensive and systemic report of the disease using previously issued, full-text available data in this article.

\section{CASE REPORT}

A case report of the patient; A 48-year-old Asian man, presented with both arm numbness and gait disturbance for 1 year. His deteriorating symptoms led him to image evaluation. Magnetic resonance imaging (MRI) of his cervical spine shows central canal stenosis of C3/4 (Grade II), C6/7 (Grade III) with changed signal intensity on spinal cord which suggests compressive myelopathy and bilateral neural foraminal stenosis of C6/7. Positive for Hoffman sign works with images.

We planned laminoplasty C4, 5, 6, and 7. On operation field we directly confirmed severe central stenosis $\mathrm{C} 6 / 7$. Complete decompression and fixation wad done. There was no problem when anesthetic induction with oral intubation and the patient tolerated well during procedures.

Immediately after the operation, he complained of hoarseness and swelling difficulty. It is common symptom after oral intubation. But uvula and tongue deviation to the right is detected on his physical examinations (Fig. 1A, B). This is a complication that has nothing to do with the surgical field of view and is not commonly known.

We checked brain MRI which showed unremarkable findings. We sent the patient to a laryngologist to check his vocal cord. On lanyngeal examination, right vocal cord median fixation was noted which suggests nerve palsy (Fig. 1C). Referring to previously reported literature, we diagnosed the patient with a disease entity of the Tapia syndrome.

The tongue deviation disappeared 4 months after surgery, but vocal cord palsy (NCP) and uvular deviation still remained (Fig. 1E, F). At 8 months after the operation, the remaining VCP and uvular 

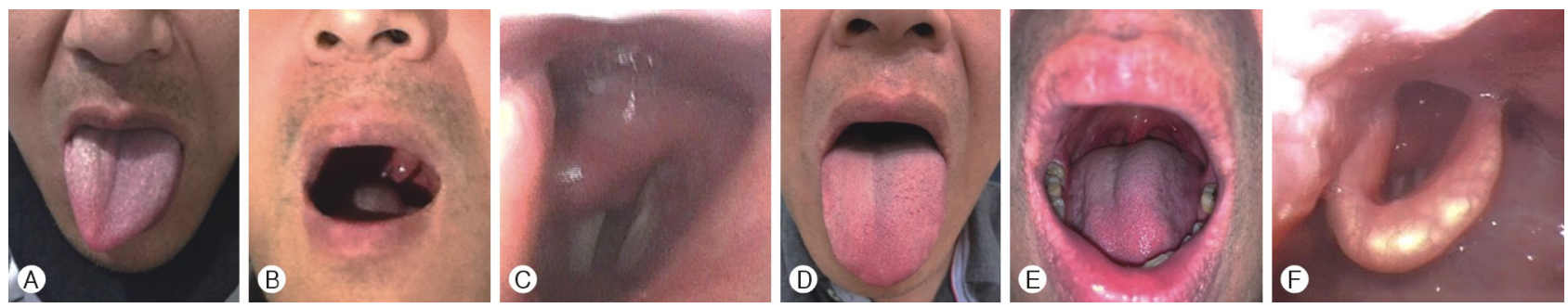

Fig. 1. Gross and laryngoscope image of the patient with cervical laminoplasty. Immediate post-operative findings of the patient (A) tongue, (B) uvula, (C) laryngoscope. Findings at 4 months after the operation (D) tongue, (E) uvula, (F) laryngoscope.

Table 1. The details of the reports which previously reports of Tapia syndrome

\begin{tabular}{|c|c|c|c|c|c|c|c|c|c|}
\hline \multirow[b]{2}{*}{ Reference } & \multirow[b]{2}{*}{ Year } & \multirow[b]{2}{*}{ Sex } & \multirow[b]{2}{*}{ Age } & \multicolumn{2}{|l|}{ Operation } & \multicolumn{2}{|c|}{ Symptoms } & \multirow{2}{*}{$\begin{array}{l}\text { Use of } \\
\text { steroids }\end{array}$} & \multirow[b]{2}{*}{$\begin{array}{l}\text { Rehabili- } \\
\text { tation }\end{array}$} \\
\hline & & & & Name & Position & $\begin{array}{l}\text { Direction of } \\
\text { involved nerves }\end{array}$ & $\begin{array}{l}\text { Other cranial nerve } \\
\text { symptoms }\end{array}$ & & \\
\hline Boisseav et al. . $^{3)}$ & 2002 & M & 42 & Shoulder arthroscopy & Upright beach chair & Lt & Soft palate palsy & Y & Y \\
\hline Tesei et al. ${ }^{19)}$ & 2006 & $\mathrm{~F}$ & 3 & Rhinoplasty & - & Rt & - & Y & Y \\
\hline Uña et al. ${ }^{211}$ & 2009 & M & 28 & Diagnostic anterior mediastinotomy & - & Bilateral & - & Y & Y \\
\hline Boğa and Aktas $^{2)}$ & 2010 & M & 35 & (Septo) rhinoplasty & - & Rt & Tongue swelling & Y & N \\
\hline Nalladaru et al. ${ }^{16)}$ & 2012 & M & 49 & Coronary artery bypass surgery & - & Rt & Soft palate palsy & Y & N \\
\hline \multirow{2}{*}{ Park et al. ${ }^{17)}$} & \multirow{2}{*}{2013} & M & 53 & Posterior foraminotomy with discectomy & Prone & Lt & - & N & N \\
\hline & & M & 56 & Cenvical laminoplasty & Prone & Lt & Tongue hypesthesia & $\mathrm{N}$ & $\mathrm{N}$ \\
\hline Lim et al. ${ }^{13)}$ & 2013 & M & 64 & Cenvical laminoplasty C3-7 & Prone & Lt & - & Y & $\mathrm{N}$ \\
\hline Emohare ef al. $\left.{ }^{6}\right)$ & 2013 & M & 17 & Posterior instrumentation and arthrodesis, $\mathrm{Tl}-\mathrm{L} 1$ & Prone & Bilateral & - & $\mathrm{N}$ & $\mathrm{N}$ \\
\hline Kang et al. ${ }^{10)}$ & 2013 & M & 47 & Cenvical laminectomy & Prone & Lt & Throat pain & Y & $\mathrm{N}$ \\
\hline Ghorbani et al. . $^{\prime}$ & 2014 & M & 27 & (Septo) rhinoplasty & - & Lt & Aspiration & Y & $\mathrm{N}$ \\
\hline \multirow[t]{2}{*}{ Ulusoy et al. ${ }^{20)}$} & 2014 & $\mathrm{~F}$ & 19 & (Septo) rhinoplasty & - & Lt & Loss of sense of taste & Y & Y \\
\hline & & M & 36 & Drainage of a neck abscess & - & Rt & - & $\mathrm{N}$ & Y \\
\hline \multirow[t]{2}{*}{ Cariati et al. .) $^{2}$} & 2016 & M & 61 & Drainage of a neck abscess & - & Rt & - & N & Y \\
\hline & & M & 42 & Shoulder open reduction & - & Rt & Loss of sense of taste & N & Y \\
\hline Aytuluk and Aktaş" & 2018 & M & 32 & Septo (rhino) plasty & - & Rt & - & Y & Y \\
\hline Kerolus et al. ${ }^{11)}$ & 2018 & $\mathrm{~F}$ & 48 & Anterior cervical discectomy and fusion & Supine & Lt & $\begin{array}{l}\text { Lt facial numbness, } \\
\text { facial palsy }\end{array}$ & N & Y \\
\hline Mumtaz et al. ${ }^{15)}$ & 2018 & M & 23 & Postoperative oral bleeding and epistaxis & - & Rt & - & $\mathrm{N}$ & Y \\
\hline Uneda et al. ${ }^{22}$ & 2018 & M & 51 & Internal fixation of a left proximal humeral fracture & Upright beach chair & Lt & - & N & N \\
\hline \multirow[t]{2}{*}{ Ghorbani et al. ${ }^{8)}$} & 2019 & M & 3 & Cosmetic malar augmentation & - & Lt & - & N & Y \\
\hline & & M & 66 & Arthroscopic repair of a right rotator cuff tear & Upright beach chair & Rt & - & $\mathrm{N}$ & $\mathrm{N}$ \\
\hline \multirow[t]{2}{*}{ Kraus et al. ${ }^{12)}$} & 2019 & M & 69 & Left arthroscopic rotator cuff repair & Upright beach chair & Lt & - & $\mathrm{N}$ & $\mathrm{N}$ \\
\hline & & M & 75 & Total shoulder arthroplasty (Rt) & Upright beach chair & Rt & - & N & N \\
\hline This study & 2021 & M & 47 & Cervical laminoplasty & Prone & Rt & Uvular deviation & Y & $\mathrm{N}$ \\
\hline
\end{tabular}

M: male; F: female; Rt: right; Lt: leff; $Y$ : yes; N: no.

deviation disappeared, so further examination and follow-up were not required.

\section{DISCUSSION}

\section{Characteristics}

To analysis further quantitatively for the disease, we checked all the cases of the disease gathering by searching of the PubMed. Only full-text available, English-language literature were included. Totally 19 reports with 24 cases were included for the analysis which also included our patient. Table 1 shows the details of the reports which include sex, age, operation, symptoms, whether to use steroids and rehabilitation
The median age was 43 years (interquartile range, 30-54) and most people were men $(87.5 \%, 21$ of 24$)$. The fields of operations are 7 for cenvical or upper thoracic spine, 6 for shoulder, 5 for nasal septum, 2 for mediastinum, 2 for neck (abscess drainage), and 2 for the other site. We'd like to noted here that all of the analyzed operations are performed not far from the intubation position. It can be concluded that all tapia syndrome occurs only in surgery around the location where compressive neuropraxia occurs. The deeper discussion about this will be mentioned in detail in the discussion on the cause of the disease.

In the direction of the injury of cranial nerve, 12 out of 24 (50\%) were right and 11 out of 24 (45.83\%) were left. There were two cases of bilateral direction of injury. There have been several reports that the occurs to the left more in the postoperative hypoglossal nerve palsy because of anatomical pathway of the nerve ${ }^{14,16,23)}$, 


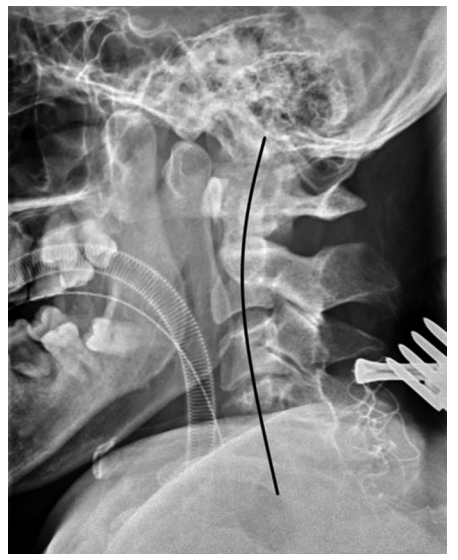

Fig. 2. Intraoperative X-ray of out case patient. The black line is an imaginary line connecting the center of the cervical body with reference to $\mathrm{C} 2$.

but the data collected in this study could not say that there is a dominant direction.

The 11 patients (45.83\%) were given glucocorticoid although the route and dosage varied and also 11 patients received postoperative rehabilitation for speech.

\section{Causes}

The cranial nerves $I X, X$, and $X I$ are anterior to the internal jugular vein and posterior to internal carotid artery immediately after they traverse the jugular foramen. The recurrent laryngeal nerve (RLN), the terminal branch of the vagus nerve at the neck level, provides motor innervation to the intrinsic muscles of the larynx except for the cricothyroid muscle and sensory innervation of the larynx.

The hypoglossal nerve is purely a motor nerve responsible for innervating the extrinsic and intrinsic muscles of the tongue. The nerve is divided into 5 segments, and this is medullary, cisternal, skull base, nasopharyngeal and oropharyngeal carotid space, and sublingual. The nerve is medial to the cranial nerve IX, $X$, and $\mathrm{XI}$ cranial nerves after they exit the cranium through the hypoglossal canal. Cranial nerve XII travels in the carotid sheath before exiting at the $\mathrm{C} 2$ level and traveling anteriorly. Cranial nerve XII then travels superior to the hyoid bone to terminate and provide motor innervation.

In previous reports, there is a common opinion that vagus and hypoglossal nerve are compressed together at the oro-hypopharynx level as the cause of the disease, but the views differ slightly in detail. Some authors insisted the these nerve be stretched against anterior surface of the transverse process of $\mathrm{Cl}$ if hyperextension of this joint ${ }^{9,19)}$. The others proposed the mechanism of the disease by inducing compression in the carotid sheath at the $\mathrm{C} 2$ level while the neck flexion pushes the mandible ramus back during surgery ${ }^{17,22}$.

There are several reports that intraoperative position can have an effect. Beach chair position on shoulder operation ${ }^{12)}$, Fowler position on nasal septum operation or intraoperative position change is reported to have a relationship ${ }^{22)}$, but it is not clear how these cause nerve injury.

Some authors insisted that large throat packs in particular cause direct lingual and hypoglossal nerve injury in operation ${ }^{14,19}$. It is meaningful in that the place where throat packing is inserted in the area where the event occurs, but a clear causal relationship needs to be confirmed.

In our institution, $X$-rays are performed during surgery to accurately confirm the surgical level. Fig. 2 is an intraoperative $X$-ray of this patient in our case. The black line in the figure is an imaginary line connecting the center of the cervical body with reference to $\mathrm{C} 2$, which shows that there was no excessive flexion or extension in this patient. In addition, there were no reports of changes in posture or throat packing during surgery. It is still difficult to explain a direct causal relationship between laminoplasty and this syndrome.

\section{Variations of the Disease}

The strict definition of tapia syndrome is postoperative, unilateral, peripheral both RLN and hypoglossal nerve palsy which cause VCP and tongue motor palsy respectively.

Most of the reported cases indicated that the disease was unilateral, but there were rare cases that occurred bilaterally,21). And isolated $\mathrm{VCP}^{24,25)}$ or hypoglossal nerve damage ${ }^{5,7)}$ cases also have been reported. Although most cases reported only VCP due to RLN damage, there are cases with uvula and soft palate palsy, including our case ${ }^{18)}$. The pharyngeal branch which innervates soft palate and uvula emerges from the vagus nerve much above the RLN.

Besides, there are reports of suspicious chorda tympani nerve or glossopharyngeal injury which presents loss of taste of tongue and lingual nerve injury which present hypoesthesia of tongue.

Taken all above together, the types of postoperative compressive neurapraxia occurring at the oropharynx level can vary, and this could be defined as tapia syndrome from a broad perspective.

\section{Diagnosis and Treatment}

Basically, it is important to check which cranial nerve palsy is present through detailed neurologic examination. In particular, in the case of the vagus nerve, the level of injury should be checked.

As mentioned above, computed tomography or MRI of the brain and neck is essential to discriminate central causes which is critical such as cerebral infarct, intracranial hemorrhage, carotid artery dissection and to exclude possible other causes such as a tumor, abscess formation.

Since Cariati et al. ${ }^{4)}$ first reported the use of a laryngoscope in this disease, this procedure is essential because it not only visualizes the VCP, but can also discriminate whether it is a symptom of laryngospasm, which occurs much more frequently after surgery.

\section{Prevention}

Previous reports proposed several other prevention methods like smooth and gentle intubation and extubation, endotracheal cuff pressures, prolonged laryngescopy ${ }^{8,12}$. But based on the previous presentations and the causes alleged in this article, It is considered to be the most important to keep an appropriate or neutral neck position and to minimize or eliminate neck movement after intuba- 
tion.

Little is known about the relationship between throat packing and the disease, but alertness should be taken as it is the procedure at the level of event which we claimed.

To cover all areas of prevention, a multidisciplinary approach including surgery, anesthesia, lanyngology, neurology or neurosurgery, and rehabilitation medicine is required.

\section{CONCLUSION}

Tapia syndrome is a very rare disease concomitant unilateral paralysis of the tongue and the vocal cord after orotracheal intubation. Little is known about the causes of the disease, but alertness should be taken as it is the procedure at the level of event which exist at C2 level. A multidisciplinary approach including surgery, anesthesia, laryngology and neurology is required to prevent and early recovery from the disease.

Our case is meaningful in that it is the first case showing the course of the disease as an image among the reported tapia syndromes, and it is the first report that comprehensively analyzes previous cases. More reports and evaluations are needed to obtain detailed information on the cause and treatment of this disease.

\section{CONFLICTS OF INTEREST}

No potential conflict of interest relevant to this article was reported.

\section{REFERENCES}

1. Aytuluk HG, Aktaş Ö: Unilateral hypoglossal nerve palsy after septoplasty under general anaesthesia. Turk J Anaesthesiol Reanim 46:241-244, 2018

2. Boğa I, Aktas S: Treatment, classification, and review of Tapia syndrome. J Craniofac Surg 21:278-80, 2010

3. Boisseau N, Rabarijaona H, Grimaud D, Raucoules-Aimé M: Tapia's syndrome following shoulder surgery. Br J Anaesth 88: 869-870, 2002

4. Cariati P, Cabello A, Galvez PP, Sanchez Lopez D, Garcia Medina B: Tapia's syndrome: pathogenetic mechanisms, diagnostic management, and proper treatment: a case series. J Med Case Rep 10:23, 2016

5. Drouet A, Straboni JP, Gunepin FX: Paralysis of the hypoglossal nerve after orotracheal intubation for general anesthesia. Ann Fr Anesth Reanim 18:811-812, 1999

6. Emohare O, Peterson E, Slinkard N, Janus S, Morgan R: Occam paradox? A variation of tapia syndrome and an unreported complication of guidewire-assisted pedicle screw insertion. Evid Based Spine Care J 4:132-136, 2013

7. Evers KA, Eindhoven GB, Wierda JM: Transient nerve damage following intubation for trans-sphenoidal hypophysectomy. Can J Anaesth 46:1143-1145, 1999

8. Ghorbani F, Tavanafar S, Eftekharian H: Tapia's syndrome after cosmetic malar augmentation: A case report. J Dent (Shiraz) 20:66-69, 2019
9. Ghorbani J, Dabir S, Givehchi G, Najafi M: Co-presentation of Tapia's syndrome and pressure alopecia--A rare event after septorhinoplasty: A case report and literature review. Acta Anaesthesiol Taiwan 52:38-40, 2014

10. Kang JH, Kim DM, Kim SW: Tapia syndrome after cervical spine surgery. Korean J Spine 10:249-251, 2013

11. Kerolus MG, Turel MK, O'Toole JE: An unusual presentation of Tapia syndrome mimicking a partial Wallenberg syndrome following anterior cervical spine surgery. J Neurosurg Anesthesiol 30:379-381, 2018

12. Kraus MB, Cain RB, Rosenfeld DM, Caswell RE, Hinni ML, Molloy MJ, et al.: Tongue tied after shoulder surgery: A case series and literature review. Case Rep Anesthesiol 2019: 5392847, 2019

13. Lim KJ, Kim MH, Kang MH, Lee HM, Park EY, Kwon KJ, et al.: Tapia's syndrome following cervical laminoplasty -A case report. Korean J Anesthesiol 64:172-174, 2013

14. Lykoudis EG, Seretis K: Tapia's syndrome: an unexpected but real complication of rhinoplasty: case report and literature review. Aesthetic Plast Surg 36:557-559, 2012

15. Mumtaz S, Henry A, Singh M: Tapia's syndrome. Anesth Prog 65:129-130, 2018

16. Nalladaru Z, Wessels A, DuPreez L: Tapia's syndrome-a rare complication following cardiac surgery. Interact Cardiovasc Thorac Surg 14:131-132, 2012

17. Park CK, Lee DC, Park CJ, Hwang JH: Tapia's syndrome after posterior cervical spine surgery under general anesthesia. J Korean Neurosurg Soc 54:423-425, 2013

18. Schoenberg BS, Massey EW: Tapia's syndrome. The erratic evolution of an eponym. Arch Neurol 36:257-260, 1979

19. Tesei F, Poveda LM, Strali W, Tosi L, Magnani G, Farneti G: Unilateral laryngeal and hypoglossal paralysis (Tapia's syndrome) following rhinoplasty in general anaesthesia: case report and review of the literature. Acta Otorhinolaryngol Ital 26:219221, 2006

20. Ulusoy H, Besir A, Cekic B, Kosucu M, Geze S: Transient unilateral combined paresis of the hypoglossal nerve and lingual nerve following intubation anesthesia. Braz J Anesthesiol 64: 124-127, 2014

21. Uña E, Gandía F, Duque JL: Tongue paralysis after orotracheal intubation in a patient with primary mediastinal tumor: a case report. Cases J 2:9301, 2009

22. Uneda C, Yano T, Imaizumi T: A case of combined cranial nerve palsy after general anesthesia. JA Clin Rep 4:74, 2018

23. Varedi P, Shirani G, Karimi A, Varedi P, Khiabani K, Bohluli B: Tapia syndrome after repairing a fractured zygomatic complex: a case report and review of the literature. J Oral Maxillofac Surg 71:1665-1669, 2013

24. Wason R, Gupta P, Gogia AR: Bilateral adductor vocal cord paresis following endotracheal intubation for general anaesthesia. Anaesth Intensive Care 32:417-418, 2004

25. Yavuzer R, Başterzi Y, Ozköse Z, Yücel Demir H, Yilmaz M, Ceylan A: Tapia's syndrome following septorhinoplasty. Aesthetic Plast Surg 28:208-211, 2004 